\title{
Cryogenic cave carbonates in the Dolomites (northern Italy): insights into Younger Dryas cooling and seasonal precipitation
}

\section{Gabriella Koltai et al.}

Correspondence to: Gabriella Koltai (gabriella.koltai@uibk.ac.at)

The copyright of individual parts of the supplement might differ from the article licence. 


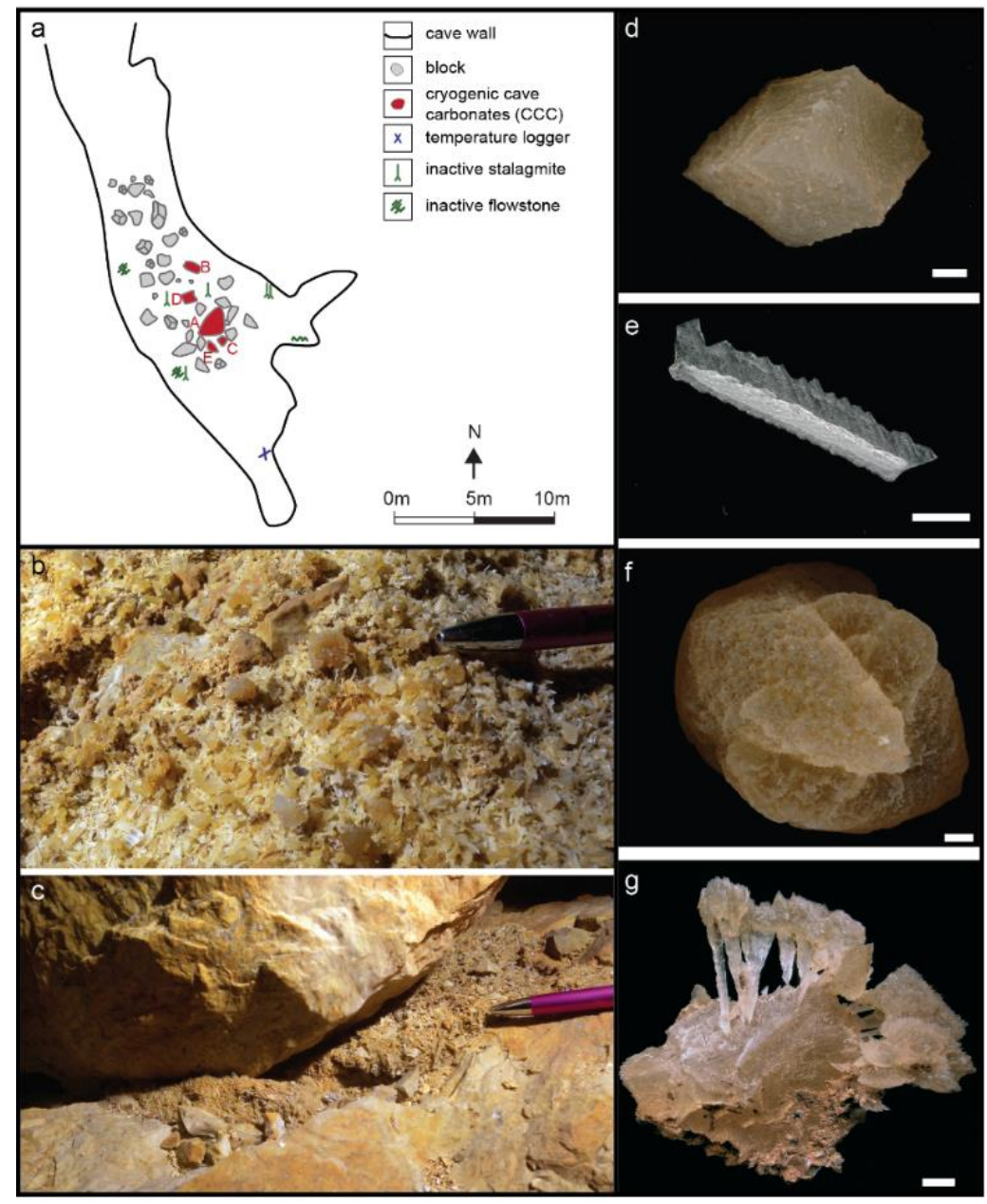

Supplementary Figure 1: Occurrence and morphological characteristics of CCC from Cioccherloch. (a) Simplified map of the lower end of the gallery showing the distribution of CCC. (b-c) CCC were found on the surface and partially beneath breakdown blocks

5 (tip of pen for scale). CCC occur in rhombic (d), skeletal (e) and beak-like (f) morphologies, and also form aggregates (g). White scale bars $1 \mathrm{~mm}$. 


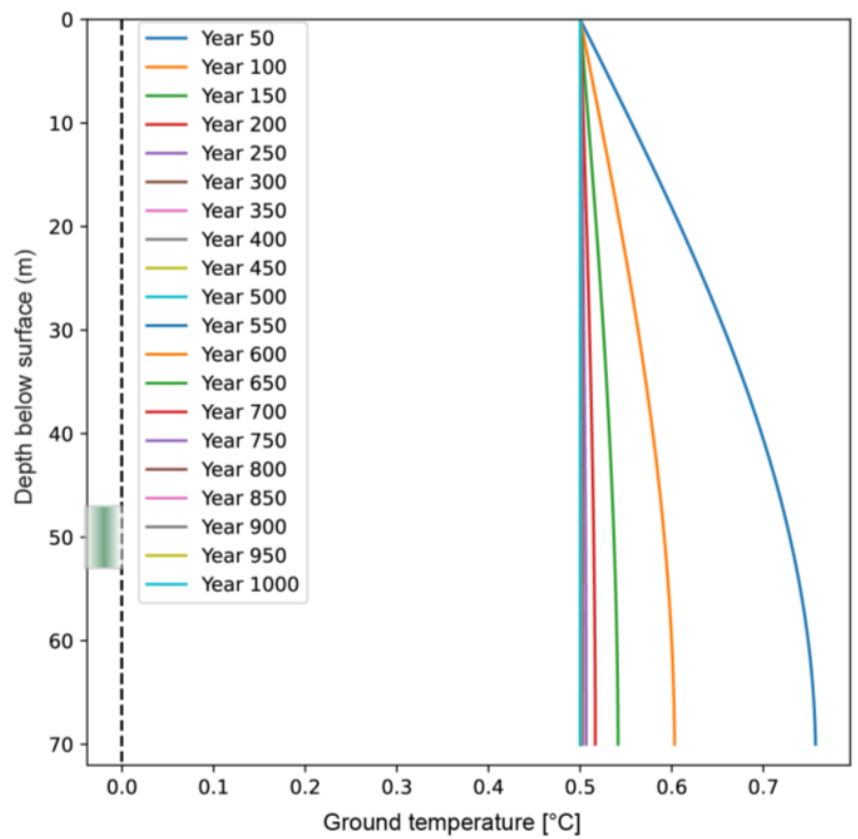

10 Supplementary Figure 2: Heat conduction model 1 simulating interstadial conditions similar to the Allerød for 1000 years (scenario 1). Modeling results are shown against depth below the surface and depict MAAT. This model uses a MAAT of $0.5^{\circ} \mathrm{C}$ and an initial ground surface temperature of $+1^{\circ} \mathrm{C}$. The rectangle with the green shading marks the "window" of possible CCC formation (-1 to $\mathrm{0}^{\circ} \mathrm{C}$ ) for the depth of the $\mathrm{CCC}$ site in Cioccherloch. 
(a)
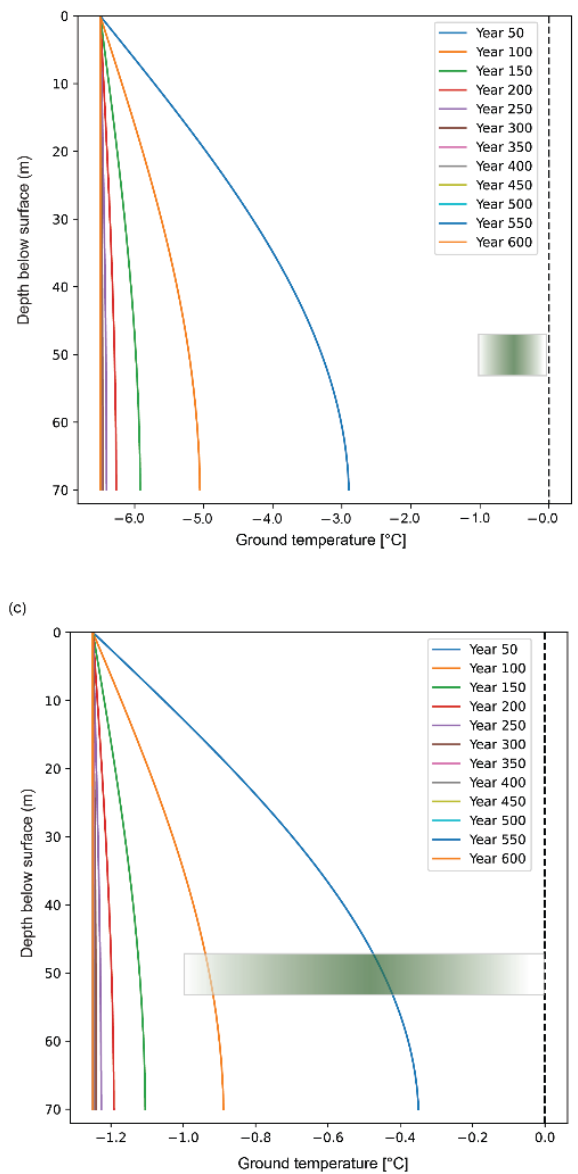
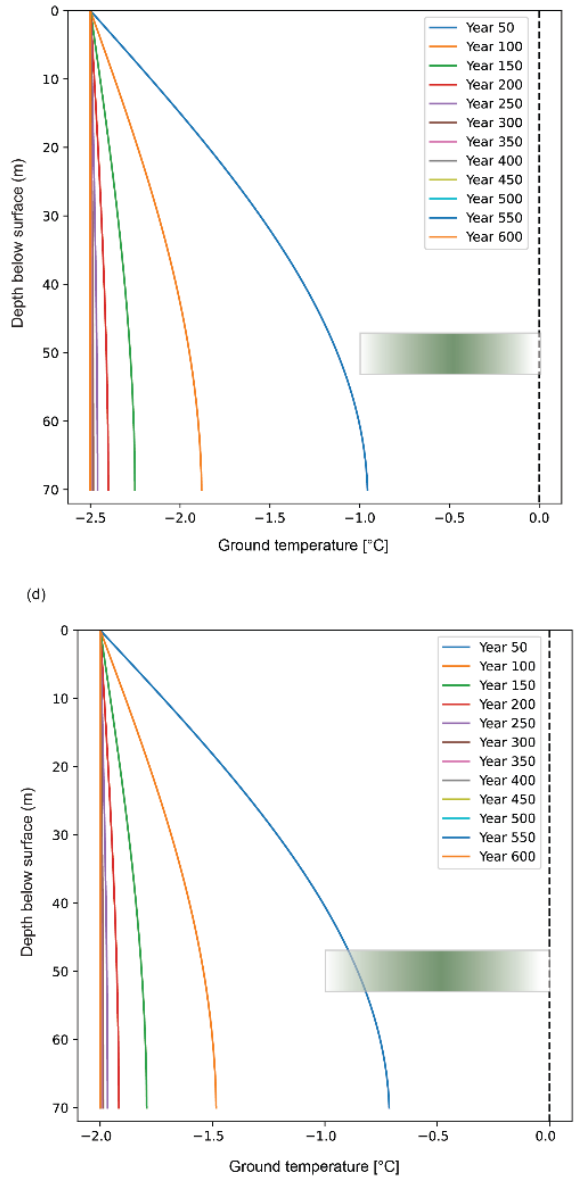

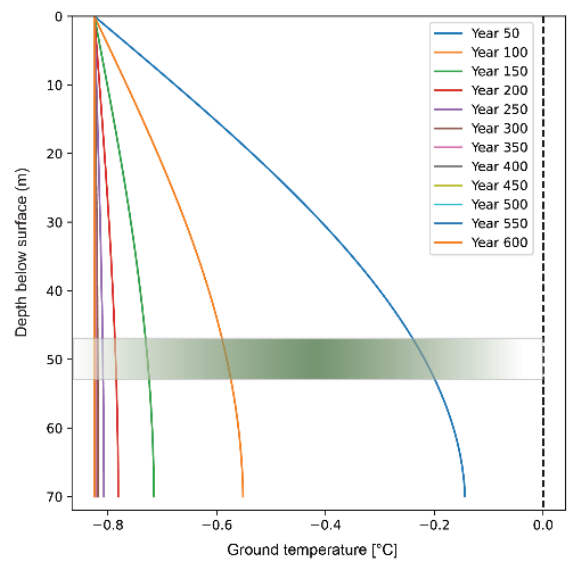

Supplementary Figure 3: Thermal models 2a-2e simulating the development and deepening of the permafrost during the early YD. These models use the final temperature profile of model 1 as initial condition. Modeling results are shown against depth below the surface and depict MAAT. Scenarios 2a, 2b, 2c, 2d and to 2e are shown in (a), (b), (c), (d) and (e), respectively. The rectangle with the green shading marks the "window" of possible $\mathrm{CCC}$ formation $\left(-1\right.$ to $\left.{ }^{\circ} \mathrm{C}\right)$ for the depth of the $\mathrm{CCC}$ site in Cioccherloch. 
(a)

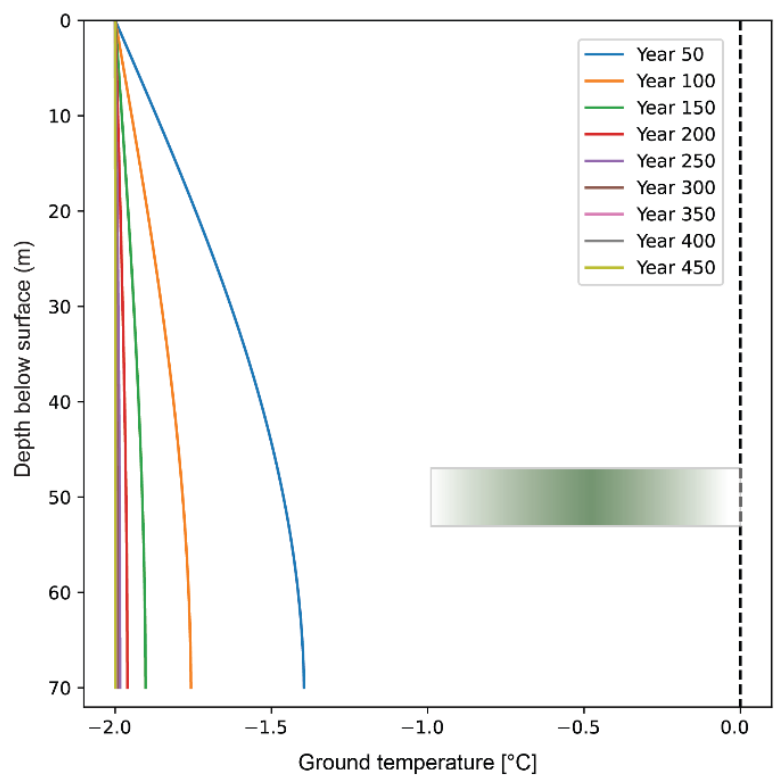

(c)

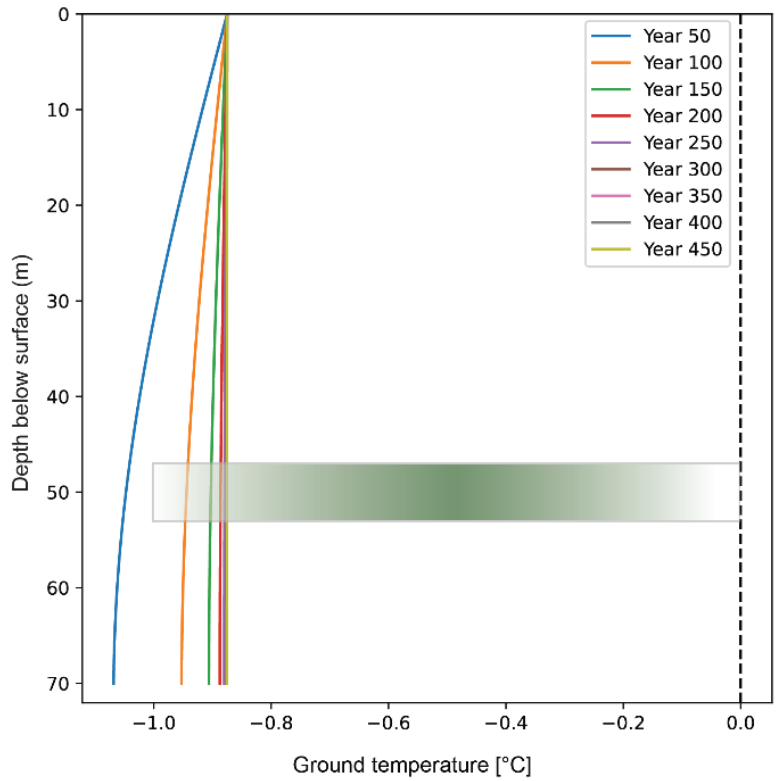

(b)

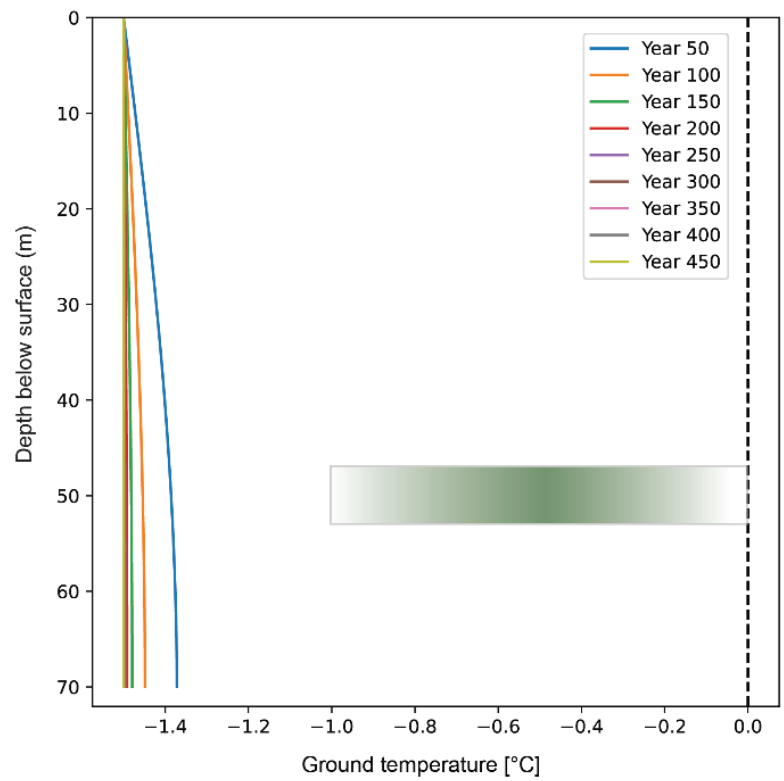

Supplementary Figure 4: Thermal models 3a-3c simulating subsurface conditions after the mid-YD transition. Modeling results are shown against depth below the surface and depict MAAT. Scenarios 3a, 3b and 3c are shown in (a), (b) and (c), respectively. The rectangle with the green shading marks the "window" of possible $\mathrm{CCC}$ formation $\left(-1\right.$ to $\left.0^{\circ} \mathrm{C}\right)$ for the depth of the $\mathrm{CCC}$ site in Cioccherloch. 
Supplementary Table 1: Stable isotope data of CCC from the different heaps in Cioccherloch.

\begin{tabular}{|c|c|c|}
\hline Sample & $\delta^{13} \mathrm{C}(\%, \mathrm{VPDB})$ & $\delta^{18} \mathrm{O}(\%$, VPDB $)$ \\
\hline FOS12-A2-1 & 5.1 & -20.2 \\
\hline FOS12-A2-2 & 5.3 & -20.8 \\
\hline FOS12-A2-3 & 5.1 & -20.8 \\
\hline FOS12-A3-1 & 4.3 & -19.2 \\
\hline FOS12-A3-2 & 4.5 & -19.2 \\
\hline FOS12-A4-1 & 4.7 & -20.4 \\
\hline FOS12-A4-2 & 4.6 & -20.0 \\
\hline FOS12-A4-3 & 4.8 & -20.7 \\
\hline FOS12-A7-1 & 5.1 & -20.8 \\
\hline FOS12-A7-2 & 5.2 & -20.6 \\
\hline FOS12-A7-3 & 5.3 & -20.9 \\
\hline FOS $12-\mathrm{A} 10-1$ & 4.5 & -19.7 \\
\hline FOS12-A10-2 & 4.3 & -18.8 \\
\hline FOS12-A12-1 & 4.0 & -16.6 \\
\hline FOS12-A12-2 & 3.4 & -16.4 \\
\hline FOS12-A22-1 & 4.7 & -19.9 \\
\hline FOS12-A22-1 & 4.8 & -20.6 \\
\hline FOS12-A22-3 & 4.8 & -20.8 \\
\hline FOS12-A22-4 & 4.6 & -19.3 \\
\hline FOS12-A1 & 3.3 & -17.7 \\
\hline FOS12-A2 & 5.0 & -20.6 \\
\hline FOS12-B2-1 & 3.0 & -17.7 \\
\hline FOS12-B4-1 & 3.0 & -16.2 \\
\hline FOS12-B4-2 & 3.4 & -16.9 \\
\hline FOS12-B3-1 & 4.0 & -19.3 \\
\hline FOS12-B3-2 & 1.9 & -13.7 \\
\hline FOS12-B3-3 & 1.3 & -12.9 \\
\hline FOS12-B5-1 & 3.7 & -18.4 \\
\hline FOS12-B5-2 & 2.8 & -16.5 \\
\hline FOS12-B6-1 & 5.0 & -20.5 \\
\hline
\end{tabular}




\begin{tabular}{|c|c|c|}
\hline FOS12-B6-1 & 5.0 & -20.9 \\
\hline FOS12-C1 & 5.1 & -21.3 \\
\hline FOS12-C2 & 5.2 & -21.1 \\
\hline FOS12-C4-1 & 4.8 & -20.4 \\
\hline FOS12-C5-1 & 4.6 & -20.7 \\
\hline FOS12-C5-2 & 4.5 & -20.5 \\
\hline FOS12-C6-1 & 5.1 & -21.5 \\
\hline FOS12-C7 & 4.9 & -21.2 \\
\hline FOS12-C8 & 5.4 & -21.4 \\
\hline FOS12-C9 & 4.9 & -20.2 \\
\hline FOS12-C10 & 4.9 & -20.0 \\
\hline FOS12-C11 & 4.2 & -18.6 \\
\hline FOS12-C12 & 4.9 & -21.1 \\
\hline FOS12-C13 & 5.0 & -21.2 \\
\hline FOS12-C14 & 5.2 & -21.0 \\
\hline FOS12-C15 & 4.3 & -19.2 \\
\hline FOS12-C16 & 5.3 & -21.8 \\
\hline FOS12-C17 & 4.9 & -21.1 \\
\hline FOS12-D1 & 2.6 & -10.1 \\
\hline FOS12-D4-2 & 2.7 & -17.5 \\
\hline FOS12-D4-3 & 2.6 & -16.3 \\
\hline FOS12-D8-1 & 5.3 & -21.2 \\
\hline FOS12-D8-2 & 5.2 & -21.0 \\
\hline FOS12-D8-3 & 4.8 & -20.0 \\
\hline FOS12-D1-1 & 4.7 & -17.6 \\
\hline FOS12-D1-2 & 4.2 & -17.4 \\
\hline FOS12-D1-3 & 4.8 & -16.0 \\
\hline FOS12-D5-1 & 1.5 & -11.1 \\
\hline FOS12-D5-2 & 4.5 & -18.0 \\
\hline FOS12-D9a & 4.2 & -19.3 \\
\hline FOS12-D9b & 4.2 & -19.2 \\
\hline
\end{tabular}




\begin{tabular}{lll} 
FOS12-E1 & 4.1 & -20.2 \\
FOS12-E2 & 3.2 & -18.3 \\
FOS12-E3-1 & 4.1 & -19.6 \\
FOS12-E3-2 & 4.3 & -20.1 \\
FOS12-E4 & 3.0 & -18.4 \\
\hline
\end{tabular}

